\title{
Effect of phosphorous-containing modified poly(vinyl alcohol) on the mechanical and flame retardant properties of polypropylene
}

\author{
S. Saucă ${ }^{1}$, M. Giamberini ${ }^{2}$, P. Cerruti ${ }^{3 *}$, M. Malinconico ${ }^{3}$, J. A. Reina ${ }^{1}$ \\ ${ }^{1}$ Departament de Química Analítica i Química Orgànica, Facultat de Química, Universitat Rovira i Virgili, Campus \\ Sescelades, Carrer Marcel·lí Domingo s/n, E-43007 Tarragona, Spain \\ ${ }^{2}$ Departament d'Enginyeria Química, Escola Tècnica Superior d'Enginyeria Química, Universitat Rovira i Virgili, \\ Campus Sescelades, Av. Països Catalans 26, E-43007 Tarragona, Spain \\ ${ }^{3}$ Institute of Polymers, Composites and Biomaterials (IPCB-CNR), Via Campi Flegrei 34, 80078 Pozzuoli (Na), Italy
}

Received 28 May 2014; accepted in revised form 9 October 2014

\begin{abstract}
Blends of polypropylene (PP) and different phosphorous-modified poly(vinyl alcohol) (PVA) derivatives synthesized on purpose, were prepared by both solvent and melt mixing, and fully characterized. Thermogravimetric analysis showed that the addition of the phosphorous-modified PVAs significantly increased thermal stability and charring of PP, probably due to their dehydration and the subsequent formation of a protective layer onto PP. SEM analysis demonstrated poor phase compatibility between PP and the polymeric additives, however acceptable dispersion of the polymeric additives was obtained. It was also observed that grafting of the modified PVA on PP occurred due to radical reactions arising during melt processing. Mechanical characterization showed that the elastic behavior of the blends was not altered with respect to neat PP, while ductility was reduced; on the other hand, impact resistance was considerably improved by blending. Slightly higher LOI values were obtained for the blends even with phosphorous content as small as $1 \mathrm{wt} \%$; reduced dripping was also observed during the burning tests for the blend samples. Moreover, cone calorimeter test results showed that heat release rate, total heat release, and fire growth rate decreased compared with PP, in particular for the blends containing residual -OH groups on the PVA backbone. Therefore, these blends can find application where the combination of toughness and fire retardancy is required, such as in the automotive industry.
\end{abstract}

Keywords: polymer blends and alloys, poly(vinyl alcohol), polypropylene, flame retardant polymers, material testing

\section{Introduction}

Polypropylene (PP) is one of the most widely used polymer because of its low cost, ease of processing as well as high water and chemical resistance. PP is used in several applications, for example housing, electronic pieces, wire and cables, automotive industry. However, it is inherently combustible [1-4], giving rise to problems such as evolution of smoke and toxic gases formed during combustion that are of particular concern among government regulatory bodies, consumers and manufacturers. A solution to reduce PP flammability is to incorporate flame retardants (FR) in the polymer structure [5-7]. As well known in the literature, FR can be introduced in the polymer matrix through a chemical modification of polymer (reactive FR) or by blending (additive FR) [8-11]. Phosphorous-containing flame retardants are widely used since they are more environmentally friendly compared to halogen-based flame retardants. The phosphorous based FR may operate in the vapor phase, suppressing the combustion of the flammable mixture through a radical mechanism which

\footnotetext{
*Corresponding author, e-mail: cerruti@ictp.cnr.it

(C) BME-PT
} 
interferes with the exothermic reactions. In the condensed phase, these FR can promote the formation of a charred layer on the polymer surface, which acts as a barrier against diffusion of volatile products as well as shielding the polymer surface from heat and air $[3,5,6,9]$.

Polymeric flame retardant additives are particularly interesting: the advantage of using them rather than conventional non-polymeric species is that they show better resistance to extraction, migration and volatilization due to their high molecular weight $[12,13]$. In a previous paper, a set of polymers which showed promising action as flame retardant additives, obtained by chemically modifying poly(vinyl alcohol) (PVA) with 4-chloroformyl-1-oxo-2,6,7trioxa-1-phosphabicyclo[2.2.2] octane (BIC), was synthesized and characterized [14]. The choice of PVA as a starting preformed polymer was due to its high availability, low cost, and relatively high reactivity. Moreover, PVA is potentially able to form char due to the presence of free hydroxyl groups. On heating, they can undergo dehydration reactions giving rise to unsaturated materials, especially in presence of phosphorous-containing moieties which can act as a dehydration catalyst source [15].The chemical structures of the prepared polymers are depicted in Figure 1. The choice of these structures was motivated by their expected different polarities, which could in turn confer different compatibility properties on blending with commodity polymers. PVA main chain and BIC moieties are quite polar. On the other hand, grafting of less polar aliphatic and aromatic ester groups onto PVA backbone lead to polymers showing a wider range of polarity.

In this work we chose PP as a thermoplastic material to be flame-retarded on blending with the above mentioned PVA derivatives. To this aim, we prepared blends by mixing the polymeric additives with PP in a suitable solvent and studied their flame retardancy behavior by thermogravimetry (TG) and limiting oxygen index (LOI) techniques. After assessing the efficiency of the PVA derivatives as flame retardant melt mixed blends were also prepared. Molecular weight, compatibility and mechanical properties of the melt mixed blends were determined through gel permeation chromatography (GPC), differential scanning calorimetry (DSC), X-Ray diffraction (XRD), dynamic mechanical thermal analysis (DMTA), scanning electron microscopy (SEM), impact and tensile tests. Finally, their flame retardancy properties were also assessed.

\section{Experimental section}

\subsection{Materials}

Moplen type polypropylene EP1X30F (MPP, containing $2 \mathrm{wt} \%$ ethylene, $M_{\mathrm{w}}=250000 \mathrm{Da}$, melt flow at $230^{\circ} \mathrm{C}=7.00-10.0 \mathrm{~g} / 10 \mathrm{~min}$ ) was provided by Montell (Italy). High molecular weight isotactic
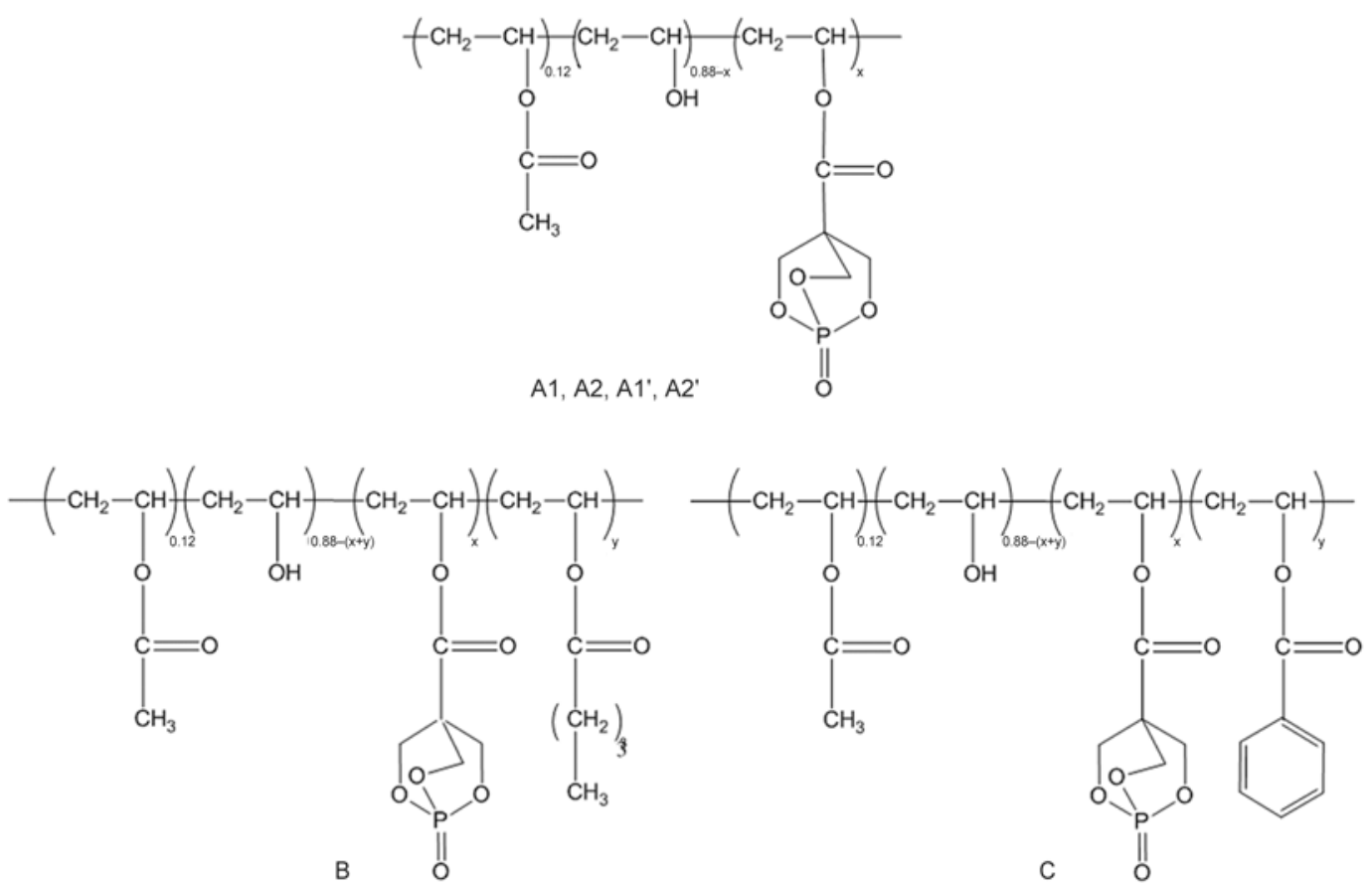

Figure 1. Chemical structure of the synthesized polymers 
Table 1. Degrees of modification and phosphorous content of the additives

\begin{tabular}{|l|c|c|c|c|}
\hline \multirow{2}{*}{ Additive } & $\begin{array}{c}\text { P obtained from ICP-AES } \\
{[\mathbf{w t} \%]}\end{array}$ & \multicolumn{3}{|c|}{ Degree of modification } \\
\cline { 3 - 5 } & 11.5 & $\mathbf{x}^{\mathbf{a}}$ & $\mathbf{x}^{\mathbf{b}}$ & $\mathbf{y}^{\mathbf{b}}$ \\
\hline A1 & 8.0 & 0.52 & & \\
\hline A2 & 11.0 & 0.23 & & \\
\hline A1' & 9.3 & 0.47 & & \\
\hline A2' & 8.6 & 0.32 & & \\
\hline B & 8.7 & & 0.44 & 0.27 \\
\hline C & & & 0.51 & 0.10 \\
\hline
\end{tabular}

${ }^{a}$ Obtained from $\% \mathrm{P}$ determined through ICP-AES

${ }^{b}$ Obtained from ${ }^{13} \mathrm{C}$ NMR

polypropylene (HIPP, $M_{\mathrm{w}}=580000 \mathrm{Da} ; T_{\mathrm{m} \text { onset }}=$ $160-165^{\circ} \mathrm{C}$ ) and all solvents were purchased from Sigma-Aldrich (Italy), and used as received. Polymeric flame retardant additives A1 and A2, used for the preparation of the solvent-assisted blends, were synthesized as previously described [14]. The additives $\mathrm{A} 1^{\prime}, \mathrm{A} 2$ ', $\mathrm{B}$ and $\mathrm{C}$, used for the melt mixed blends, were prepared through the same procedure, but using a higher amount of reagents ( $5 \mathrm{~g}$ of PVA). The degrees of modification and phosphorous content of the additives, determined through inductively coupled plasma-atomic emission spectroscopy (ICP-AES) and ${ }^{13} \mathrm{C}$ NMR, are listed in Table 1.

\subsection{Blends preparation}

\subsubsection{Blends prepared by dissolution}

$4.5 \mathrm{~g}$ of HIPP and 1,1,2,2-tetrachloroethane $(100 \mathrm{~mL})$ were introduced in a round bottomed flask provided with magnetic stirrer. The mixture was heated under stirring up to $100^{\circ} \mathrm{C}$ to completely solubilise PP, then it was cooled down at $80^{\circ} \mathrm{C}$, and the appropriate amount of selected additive was added. The mixture was further driven to reflux and stirred for two hours. Subsequently, the solvent was removed by rotary evaporation and the resulting material was dried under vacuum at $70^{\circ} \mathrm{C}$ for $1 \mathrm{~h}$, then at room temperature for $24 \mathrm{~h}$. In all cases, proper amounts of HIPP and polymeric additive were selected to prepare $5 \mathrm{~g}$ of blend. About $1 \mathrm{~g}$ of blend was pressed in a preheated press at $165^{\circ} \mathrm{C}$ and $2.5 \mathrm{~atm}$ for 1 hour in order to get bars $\left(70 \times 6 \times 3 \mathrm{~mm}^{3}\right)$. These processing conditions were chosen in order to avoid thermal

Table 2. Blends prepared by solvent dissolution

\begin{tabular}{|c|c|c|c|}
\hline Blend & Additive & $\begin{array}{c}\text { Additive content } \\
{[\mathbf{w t} \% \mathbf{]}}\end{array}$ & $\begin{array}{c}\text { Phosphorous content } \\
{[\mathbf{w t} \% \mathbf{]}}\end{array}$ \\
\hline B11 & A1 & 8.6 & 1.0 \\
\hline B12 & A1 & 4.3 & 0.5 \\
\hline B13 & A2 & 6.2 & 0.5 \\
\hline
\end{tabular}

degradation of the additives. Table 2 lists the blends prepared in this way. These samples were characterized by means of TG and LOI measurements.

\subsubsection{Blends prepared by melt mixing}

Melt mixing was carried out in a Brabender Plastograph EC (Germany) twin screw mixer at $175^{\circ} \mathrm{C}$ with a screw rate of $40 \mathrm{rpm}$. Proper amounts of polypropylene (MPP) and polymeric additive were selected to prepare $50 \mathrm{~g}$ of blend. The flame retardant additives were added after the MPP melted, and the resulting blend was further mixed for $5 \mathrm{~min}-$ utes. Then the material was removed, left to cool and cut in pellets. The pellets were hot-pressed using a Collin P200E bench top press, under a pressure of 100 bar at $165^{\circ} \mathrm{C}$ for 3 minutes, to obtain thin films (average thickness $150 \mu \mathrm{m}$ ), or at $175^{\circ} \mathrm{C}$ for $5 \mathrm{~min}$ utes, to obtain plates of $3 \mathrm{~mm}$ thickness. Thin films samples were used to perform Fourier transform infrared (FTIR) spectroscopy, TG, DSC, XRD and tensile tests, while the plates were cut in bars and used for DMTA, Charpy impact tests, cone calorimeter tests and LOI measurements. The blends prepared in this way are listed in Table 3.

\subsection{Characterization techniques}

Transmission FTIR analysis was performed using a Nicolet Nexus FTIR spectrophotometer (USA). Spectra were collected using 32 scans at $4 \mathrm{~cm}^{-1}$ resolution, in the $400-4000 \mathrm{~cm}^{-1}$ range.

The number-average $\left(M_{\mathrm{n}}\right)$, weight-average $\left(M_{\mathrm{w}}\right)$ molecular weights and intrinsic viscosities were estimated by GPC using a Waters Alliance GPC V2000 system (USA), equipped with refractive index and viscosimetric detectors, using two consecutive Polymer Laboratories (UK) mixed columns with 1,2-dichlorobenzene (DCB) at $145^{\circ} \mathrm{C}$ as eluent $\left(0.8 \mathrm{~mL} \cdot \mathrm{min}^{-1}\right)$. The equipment was calibrated with polystyrene standards.

LOI measurements were performed in triplicate in vertical tests on a Stanton Redcroft FTA (UK) flammability unit provided with an oxygen analyzer, previously calibrated with polystyrene standard

Table 3. Blends prepared by melt mixing

\begin{tabular}{|c|c|c|c|}
\hline Blend & Additive & $\begin{array}{c}\text { Additive content } \\
{[\mathbf{w t} \% \mathbf{]}}\end{array}$ & $\begin{array}{c}\text { Phosphorous content } \\
{[\mathbf{w t} \% \mathbf{]}}\end{array}$ \\
\hline $\mathrm{B} 14$ & $\mathrm{~A} 1^{\prime}$ & 9.0 & 1 \\
\hline $\mathrm{B} 15$ & $\mathrm{~A}^{\prime}$ & 10.8 & 1 \\
\hline $\mathrm{B} 16$ & $\mathrm{~B}$ & 11.6 & 1 \\
\hline $\mathrm{B} 17$ & $\mathrm{C}$ & 11.6 & 1 \\
\hline
\end{tabular}


bars. The dimensions of the polymer bars prepared by hot pressing were $70 \times 6 \times 3 \mathrm{~mm}^{3}$.

Cone calorimeter (CC) tests were performed in duplicate by a Fire Testing Technology (UK) cone calorimeter. The samples with the dimension of $60 \times 60 \times 3 \mathrm{~mm}^{3}$ were exposed to a radiant cone at a heat flux of $35 \mathrm{~kW} \cdot \mathrm{m}^{-2}$.

TG analysis of blends prepared by dissolution was carried out on a Mettler TGA/SDTA851e/LF/1100 (Switzerland) device at a heating rate of $10^{\circ} \mathrm{C} \cdot \mathrm{min}^{-1}$ up to $800^{\circ} \mathrm{C}$ under nitrogen atmosphere (flow rate $=$ $\left.100 \mathrm{~mL} \cdot \mathrm{min}^{-1}\right)$. For the blends prepared by melt mixing, TG analysis was performed on a Perkin Elmer Pyris Diamond TG-DTA thermogravimetic analyzer (USA) under the same conditions, but in this case prior to the heating ramp the samples were subjected to a 30 minutes isotherm at $80^{\circ} \mathrm{C}$ to remove the moisture that could be absorbed after the melt processing. DSC analyses were performed on a Mettler Toledo DSC Star 822e (Switzerland) calorimeter at a heating/cooling rate of $10 \mathrm{C} \cdot \mathrm{min}^{-1}$ in a nitrogen atmosphere. Melting temperatures and enthalpies were calculated from second heating scans. The crystallinity degree of MPP and its blends was calculated by using $\Delta \mathrm{H}^{\circ}$ melting $=209 \mathrm{~J} \mathrm{~g}^{-1}$, reported as the melting enthalpy of $100 \%$ crystalline PP [16].

XRD experiments were performed using a Philips PW 1710 (Netherlands) diffractometer with a rotating anode generator and a wide-angle power goniometer. The used radiation was unfiltered $\mathrm{Cu} \mathrm{K} \alpha$, with $40 \mathrm{kV}$ voltage and $20 \mathrm{~mA}$ intensity. The scan rate was $1^{\circ} \cdot \mathrm{min}^{-1}$ over a diffraction angle $2 \theta$ ranging between 2 and $40^{\circ}$. The evaluation of the degree of crystallinity for each sample was obtained from the ratio between the area under the crystalline peaks and the total area under the diffraction curve. The separation of the crystalline peaks from the amorphous part was achieved by curve fitting using Gaussian functions by means of Origin 8.0 software.

A Perkin Elmer Pyris Diamond DMTA (USA) in the dual cantilever flexural mode was used to study the dynamic mechanical thermal behavior of the blends. Rectangular specimens $50 \mathrm{~mm}$ long, $10 \mathrm{~mm}$ wide, $3 \mathrm{~mm}$ thick were analyzed. The samples were conditioned in an environmental chamber at $25^{\circ} \mathrm{C}$ and $50 \%$ relative humidity $(\mathrm{RH})$ for 7 days prior to testing. The tests were run at a heating rate of $3^{\circ} \mathrm{C} \cdot \mathrm{min}^{-1}$ from -80 to $140^{\circ} \mathrm{C}$ under nitrogen. Oscillation frequency and amplitude were $1 \mathrm{~Hz}$ and $5 \mu \mathrm{m}$, respectively. $T_{\mathrm{g}}$ was taken as the peak value of $\tan \delta$ curves.
Charpy impact tests were performed on a CEAST 6545 (Italy) apparatus according to ASTM standard test method D256-06. A standard notch $(3.5 \mathrm{~mm}$ long) was applied to the rectangular shaped rod sample with dimensions of $60 \times 60 \times 3 \mathrm{~mm}^{3}$. The notch was in the opposite direction to the striking hammer. A Philips XL20 (Netherlands) Scanning electron microscope (SEM) was used to examine the morphology of the cross-section of specimens subjected to impact tests. Samples were metallised before the observation with a gold-platinum mixture by means of a BalTec MED020 (UK) coater.

Tensile tests were performed on an Instron 5564 (USA) dynamometer equipped with a $100 \mathrm{~N}$ load cell on test specimens prepared according to ASTM D882-02 standard test method. The test samples were 'dog-bone' shaped $22 \mathrm{~mm}$ long, $4 \mathrm{~mm}$ wide. The thickness $(0.1-0.2 \mathrm{~mm})$ was measured at different points for each specimen and its average value was introduced in the Instron Merlin calculation software. The tests were performed using 5-8 specimens for each sample. The measurements were carried out at an elongation rate of $20 \mathrm{~mm} \cdot \mathrm{min}^{-1}$ at room temperature after the samples were conditioned for 24 hours at $50 \% \mathrm{RH}$.

\section{Results and discussion}

\subsection{Characterization of the blends obtained by dissolution}

As a preliminary study, we prepared blends of PP with flame retardant additives by solvent dissolution, using a polypropylene grade with high molecular weight and melting point (HIPP). The HIPP blends were prepared by dissolution in hot 1,1,2,2tetrachloroethane (Table 2). Additive contents lower than $10 \mathrm{wt} \%$ were used, since higher amounts would have affected negatively the mechanical properties of PP. Therefore blends containing 1 or $0.5 \mathrm{wt} \%$ of phosphorous were prepared, to evaluate the effect of the additive amount on the flame retardancy of polypropylene.

The obtained blends were studied by TG and LOI techniques. The thermogravimetric curves under nitrogen are shown in Figure 2, and the relative data are listed in Table 4. From the figure, a slight weight loss was observed for the blends at about $250^{\circ} \mathrm{C}$, associated to polymeric additives decomposition (mainly dehydration of the vinyl alcohol moieties). Moreover, in the blends the main weight loss process was significantly delayed $\left(>100^{\circ} \mathrm{C}\right)$, and a residual 
Table 4. Thermogravimetric and LOI results of neat HIPP and its blends

\begin{tabular}{|c|c|c|c|c|c|c|}
\hline Sample & Additive & $\begin{array}{c}\text { Phosphorous content } \\
{[w t \%]}\end{array}$ & $\begin{array}{c}\mathbf{T}_{\text {onset }}{ }^{\mathrm{a}} \\
{\left[{ }^{\circ} \mathbf{C}\right]}\end{array}$ & $\begin{array}{l}\mathbf{T}_{\max }{ }^{\mathrm{b}} \\
{\left[{ }^{\circ} \mathbf{C}\right]}\end{array}$ & $\begin{array}{c}\text { Char yield at } 600^{\circ} \mathrm{C} \\
[\%)]\end{array}$ & $\begin{array}{l}\text { LOI } \\
{[\%]}\end{array}$ \\
\hline HIPP & & & 297 & 415 & & $17.3 \pm 0.3$ \\
\hline B11 & A1 & 1.0 & 408 & 463 & 6.0 & $18.7 \pm 0.4$ \\
\hline $\mathrm{B} 12$ & A1 & 0.5 & 416 & 463 & 2.5 & $17.7 \pm 0.2$ \\
\hline B13 & A2 & 0.5 & 421 & 463 & 2.9 & $18.2 \pm 0.4$ \\
\hline
\end{tabular}

${ }^{\mathrm{a}}$ Onset temperature of the main weight loss process

${ }^{b}$ Temperature of the maximum rate of weight loss

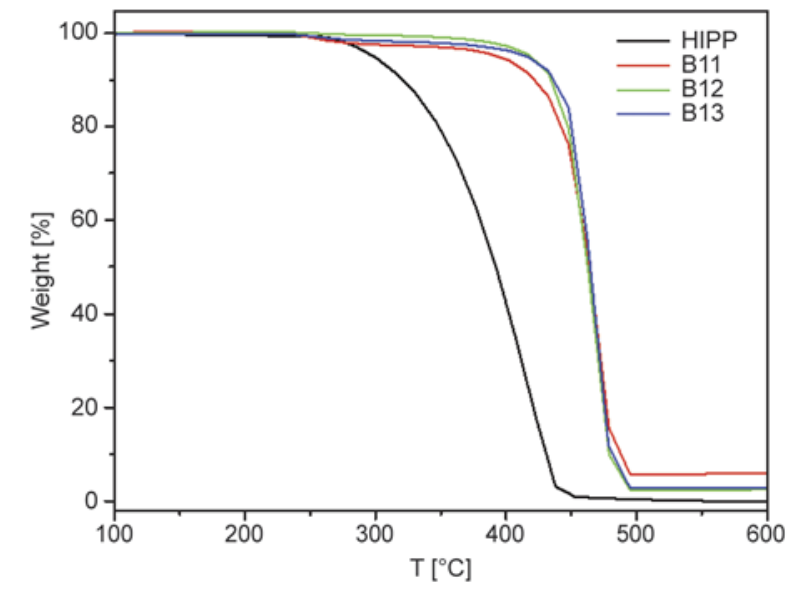

Figure 2. TG curves of neat HIPP and its blends in nitrogen atmosphere

char was formed at high temperature, while pure HIPP completely volatilized below $500^{\circ} \mathrm{C}$. These results suggest that the additives can confer flame retardancy to $\mathrm{PP}$. In this respect, A2 was likely more effective than A1, since B13 showed higher $T_{\text {onset }}$ and char yield with respect to B12. This slightly higher effectiveness shown by A2 can be related with its larger hydroxyl content (see Table 1), if we reasonably assume that dehydration is the first step of the additives decomposition.

The results of LOI measurements are reported in Table 4 . The LOI values of the blends were slightly higher than that of neat HIPP. Therefore, LOI data also confirmed that flame retardancy was conferred by A1 and A2 to HIPP. In particular, the highest LOI value was obtained for the blend containing the highest phosphorous amount (B11), while at low phosphorous content the LOI value was higher when the blend contained more hydroxyl groups (B13). This result was in agreement with TG data.

\subsection{Chemical characterization of melt mixed blends}

Once the effectiveness of the additives as flame retardants was assessed, the modified PVAs were blended to PP through melt mixing, which is a more technologically feasible processing technique compared to solvent blending. For melt mixing, we selected a Moplen type polypropylene containing $2 \mathrm{wt} \%$ ethylene (MPP) as matrix. MPP had higher flexibility than HIPP, and Moplen type PPs have been used for different applications in automotive industry [17-20] MPP was blended with $\mathrm{A}^{\prime}, \mathrm{A} 2^{\prime}, \mathrm{B}$ and $\mathrm{C}$ at $175^{\circ} \mathrm{C}$ and $40 \mathrm{rpm}$ for $5 \mathrm{~min}$. For each blend, the amount of the polymeric additive was selected in order to get a phosphorous content of $1 \mathrm{wt} \%$. In Table 3 the blends formulations are listed.

In order to probe the possibility that MPP or the polymeric additives partially degraded during the blending process, the obtained blends were characterized by FTIR and GPC. In general, FTIR spectra of the blends showed peaks due to MPP and the corresponding additive. The main MPP bands appeared at $3000-2850 \mathrm{~cm}^{-1}$ (C-H stretching) and 1500 $1350 \mathrm{~cm}^{-1}$ (C-C stretching). All the blends showed signals due to the additives at $3600-3400 \mathrm{~cm}^{-1}$ $(\mathrm{O}-\mathrm{H}), 1730 \mathrm{~cm}^{-1}(\mathrm{C}=\mathrm{O})$ and $856 \mathrm{~cm}^{-1}$ (skeleton vibration of caged bicyclic phosphate). It should be noted that no additional bands appeared in the blends with respect to virgin MPP and additives. This suggests that degradation upon blending, if any, occurred to a low extent. As an example, Figure 3 shows the spectrum of virgin MPP, the polymeric additive $B$ and the corresponding blend (B16).

$\mathrm{GPC}$ analysis was performed in DCB at $145^{\circ} \mathrm{C}$. The obtained data are collected in Table 5. For the sake of comparison, GPC analysis was also performed on unprocessed MPP and on a MPP sample processed analogously to the blends.

The polydispersity $\left(M_{\mathrm{w}} / M_{\mathrm{n}}\right)$ of the unprocessed MPP is rather high, typical of a PP synthesized in the presence of Ziegler-Natta catalysts [21]. As can be seen, molecular weights and polydispersity of processed MPP were lower than those of unprocessed polymer pellets. Thus, melt-mixing processing of neat MPP brought about slight degradation of the polymer. The decrease of polydispersity is consistent with 'con- 


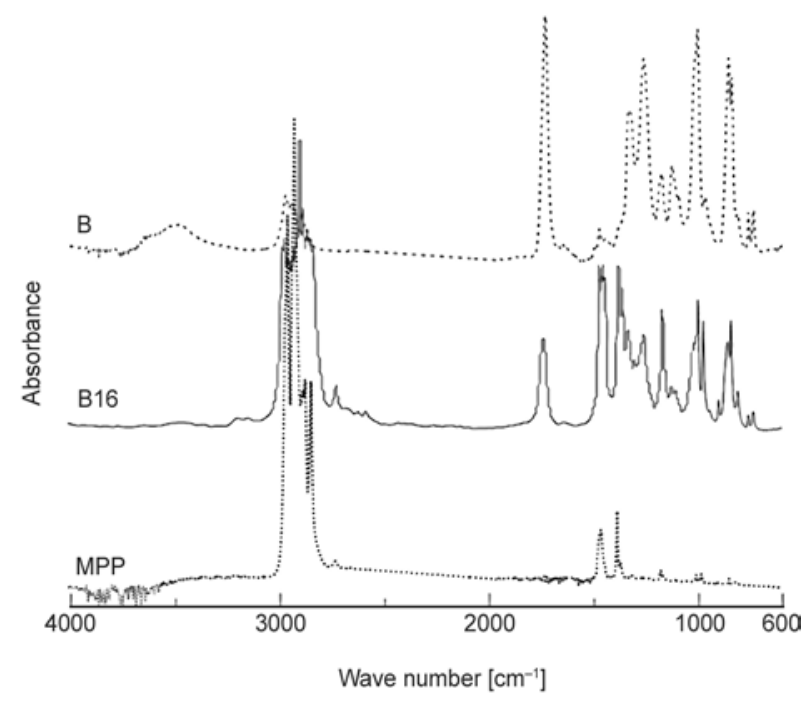

Figure 3. FTIR spectrum of virgin MPP, the additive B, and the corresponding blend B16

trolled PP degradation' principles, where the highest molecular weight chains are statistically more likely to undergo radical-mediated scission [22].

Although the polymeric additives were rather insoluble in DCB, when they were incorporated into the blends a significant fraction turned to be dissolved

Table 5. GPC data of neat MPP and its blends

\begin{tabular}{|l|c|c|c|c|}
\hline \multicolumn{1}{|c|}{ Sample } & Additive & $\begin{array}{c}\mathbf{M}_{\mathbf{w}}{ }^{\mathbf{a}} \\
{[\mathbf{D a}]}\end{array}$ & $\mathbf{M}_{\mathbf{w}} / \mathbf{M}_{\mathbf{n}}{ }^{\mathbf{b}}$ & $\begin{array}{c}\mathbf{M}_{\text {peak }}{ }^{\mathbf{c}} \\
{[\mathbf{D a}]}\end{array}$ \\
\hline Unprocessed MPP & - & 254000 & 6.8 & 159000 \\
\hline Processed MPP & - & 218000 & 4.5 & 136000 \\
\hline B14 & $\mathrm{A}^{\prime}$ & 218000 & 4.8 & 139000 \\
\hline B15 & $\mathrm{A}^{\prime}$ & 229000 & 5.2 & 144000 \\
\hline B16 & $\mathrm{B}$ & 235000 & 4.8 & 145000 \\
\hline B17 & $\mathrm{C}$ & 278000 & 4.6 & 159000 \\
\hline
\end{tabular}

${ }^{a}$ weight-average molecular weight

${ }^{\mathrm{b}}$ polymer polydispersity

cpeak of the GPC curve

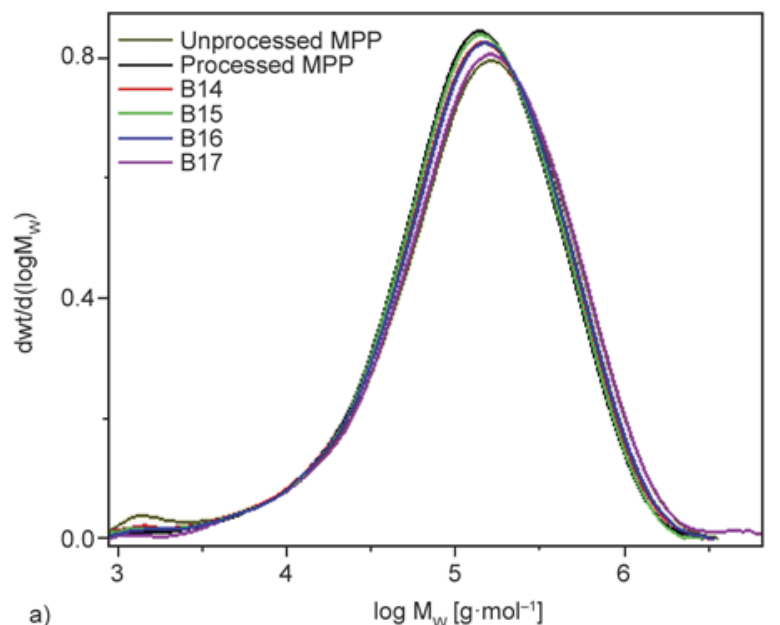

in the solution subjected to GPC characterization. Nevertheless, as can be observed from Figure 4a and Table 5, the GPC curves of the blends were similar to that of neat processed MPP, leading to comparable $M_{\mathrm{w}}$ and polydispersity, and neither peaks related to the presence of the additive, nor bimodal patterns of the molecular-mass curves were observed. The blend B17 is an exception to this general behaviour, since its GPC chromatogram showed a minor portion of higher molecular weight chains.

These findings suggest that the polymeric additives could interact with the polypropylene phase, forming physical or chemical associates having a slightly larger hydrodynamic volume than that of plain MPP, which were not separated during the elution run. This could also explain the increase in $M_{\mathrm{w}}$ observed for B17, in which the bulky pendant substituent can modify the size of the dissolved polymer adduct, thus yielding increased values of molecular weight [23].

A further confirmation of this hypothesis can be obtained by the Mark-Houwink-Sakurada (MHS) plots, Figure $4 b$, in which the intrinsic viscosity is plotted as a function of $M_{\mathrm{w}}$. MHS plots are widely used for the analysis of polymer structure, as they reflect structural changes in the polymer, such as branching and chain rigidity [24]. The slope described by the Mark-Houwink exponent can vary between 0 for solid spheres and 2 for rod-shaped structures.

From the figure, it is observed that while all samples showed comparable curve slope values of about 0.71 (typical of linear flexible chains in good solvents), the processed MPP sample displayed higher values of viscosity throughout the range of

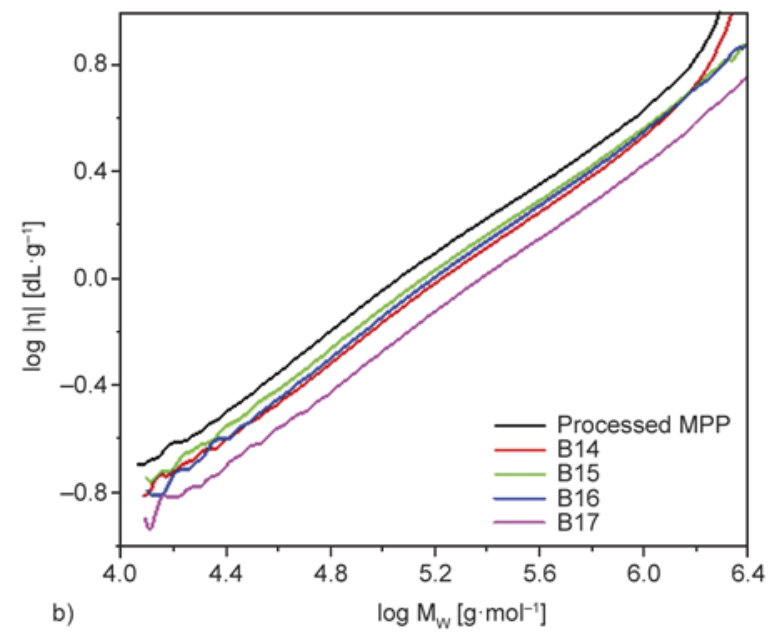

Figure 4. GPC chromatograms (a) and Mark-Houwink-Sakurada plots (b) of neat MPP and its blends 


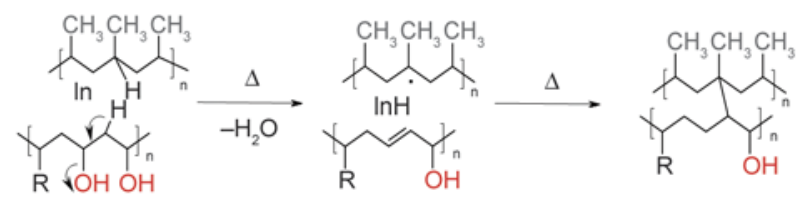

Figure 5. Scheme of the possible reactions involved in PVA grafting onto PP

$M_{\mathrm{w}}$ values analyzed. This suggests that polypropylene molecules in the blends present chain branching [25], due to the interaction of MPP with the modified PVAs. This can be due to some radical reactions that may occur between additives and matrix, as depicted in Figure 5. Usually, radical formation occurs in the presence of an initiator, identified as [In] in the figure [26, 27], which in this case may be represented by the metal particles of the equipments used for processing. Also, we should take into account that a small part of the PVAs additives may undergo dehydration reactions, leading to double bond formation, which can react with the polypropylene free radicals that could be formed during processing at high temperature.

\subsection{Crystallinity of the melt mixed blends}

In order to study the effect of the additives on the polypropylene crystallinity, DSC and XRD experiments were performed. The DSC thermograms of the processed MPP showed a melting endotherm spanning between 143 and $161^{\circ} \mathrm{C}$. The DSC data of the blends revealed that the melting temperature of polypropylene was not apparently affected by the addition of the flame retardant additives (see Table 6), indicating the absence of interactions such as cocrystallization within the polypropylene phase [28], as well as poor compatibility of the flame retardants with polypropylene. Since the glass transition signal from DSC traces was rather weak and broad, the $T_{\mathrm{g}}$ of the blends were determined through DMTA (see Section 3.4).
Melting enthalpy values were used to calculate the crystallinity of MPP and blends. As can be seen from Table 6 , the degree of crystallinity of MPP remained unaltered after blending with the flame retardant additives, with the exception of the blend B16, for which a slight increase in crystallinity was observed.

From the X-ray diffractograms (Figure 6) can be observed that the monoclinic $\alpha$ form of PP was present in all samples, and no peaks associated with the hexagonal $\beta$ form (usually detected at $2 \theta=$ $16.1^{\circ}$ ) were visible [29]. This is in agreement with the observation that isotactic polypropylene prepared with the traditional heterogeneous Ziegler-Natta catalysts generally exist in the stable $\alpha$ form [30].

The degree of crystallinity for each sample was obtained also by XRD as detailed in the experimental part. In this approach, the amorphous contribution to the scattering was taken into account through a broad diffraction band. From Table 6, which shows the degrees of crystallinity obtained by XRD and DSC, it can be observed that the results obtained by the two techniques are comparable. Moreover, the blends did not present significant changes in comparison with virgin MPP, with the exception of B16, which contain the polymer $\mathrm{B}$ as an additive. The latter has a different chemical structure compared to

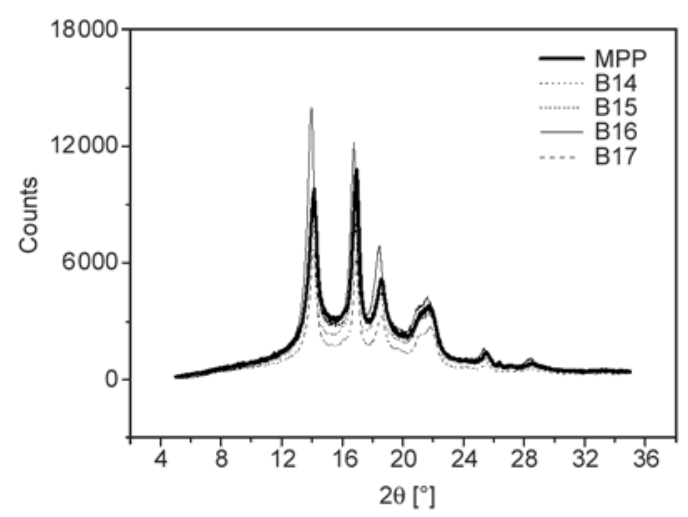

Figure 6. X-ray diffractograms of virgin MPP and its blends

Table 6. Melting temperatures and enthalpies, $T_{\mathrm{g}}$ and crystallinity degrees of MPP and its blends

\begin{tabular}{|c|c|c|c|c|c|c|}
\hline Sample & $\begin{array}{l}\mathbf{T}_{\text {peak }} \\
{\left[{ }^{\circ} \mathbf{C}\right]}\end{array}$ & $\begin{array}{c}\Delta \mathbf{H}_{1}{ }^{\mathbf{a}} \\
{\left[\mathrm{J} \cdot \mathrm{g}^{-1}\right]}\end{array}$ & $\begin{array}{c}\Delta \mathbf{H}_{2}{ }^{\mathrm{b}} \\
{\left[\mathrm{J} \cdot \mathrm{g}^{-1}\right]}\end{array}$ & $\begin{array}{c}\mathbf{T}_{\mathbf{g}} \mathbf{c} \\
{\left[{ }^{\circ} \mathbf{C}\right]}\end{array}$ & $\begin{array}{c}\text { Crystallinity from DSC }^{d} \\
{[\%]}\end{array}$ & $\begin{array}{c}\text { Crystallinity from XRD } \\
{[\%]}\end{array}$ \\
\hline MPP & 154 & 83 & 83 & -2.3 & 40 & 37 \\
\hline B14 & 153 & 73 & 80 & -2.8 & 38 & 43 \\
\hline $\mathrm{B} 15$ & 154 & 70 & 78 & -2.7 & 37 & 37 \\
\hline B16 & 154 & 81 & 89 & 0.1 & 43 & 46 \\
\hline $\mathrm{Bl} 7$ & 155 & 73 & 80 & -5.6 & 39 & 41 \\
\hline
\end{tabular}

${ }^{\mathrm{a}}$ Melting enthalpy per gram of blend

${ }^{b}$ Melting enthalpy per gram of MPP

${ }^{\mathrm{c}}$ Glass transition temperature obtained from DMTA

${ }^{\mathrm{d}}$ Crystallinity degree obtained from $\Delta H_{2}$ 
the other phosphorous containing additives. In fact, the presence of aliphatic butyl chains is able to increase the compatibility of the additive with the matrix, as also showed by SEM analysis (see Section 3.4). This entails that the additive particles can increase PP crystallinity acting as heterogeneous nucleating agents.

\subsection{Dynamic mechanical thermal, morphological and mechanical properties}

In order to get reliable $T_{\mathrm{g}}$ values for the MPP blends, DMTA measurements were carried out. The dynamic viscoelastic curves for the neat MPP and the blends with the modified PVAs are shown in Figure 7. All the storage modulus versus temperature curves experienced a gradual decline with temperature increasing from -80 to $130^{\circ} \mathrm{C}$ [31]. MPP exhibited two distinct relaxations peaks. The $\alpha$-relaxation, at about $81^{\circ} \mathrm{C}$, relates to slip mechanism of polymer chains in the crystallites [32]. The $\beta$-relaxation $\left(-2.3^{\circ} \mathrm{C}\right)$ is assigned to the motion of the main chain in the amorphous regions, thus can be regarded as the glass transition temperature [33].

The $\tan \delta$ curves of the blends showed slight $T_{\mathrm{g}}$ value changes with respect to the parent polypropylene (Table 6). In particular, a small increase was ascribed to B16, while B17 displayed a slightly anticipated glass transition (peak at $-5.6^{\circ} \mathrm{C}$ ). The latter result suggests that in the B17 blend the segmental mobility in the amorphous phase was increased, due to the presence of polymer chains bearing bulky aromatic pendants, as already evidenced by the GPC analysis. On the other hand, the increase in $T_{\mathrm{g}}$ observed for B16 can be related to the increase in crystallinity of this sample, as detected through DSC and XRD analysis (see Section 3.3). It is expected that crystallization can impose constraints on chain

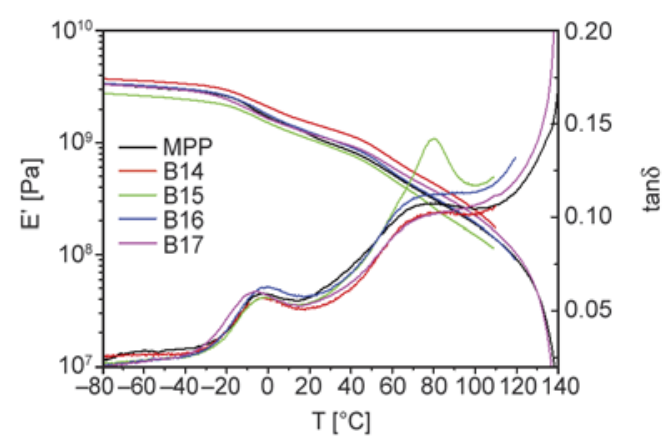

Figure 7. Elastic modulus $\left(E^{\prime}\right)$ and loss factor $(\tan \delta)$ versus temperature for neat MPP and its blends obtained by melt mixing mobility, thus yielding increased values of glass transition temperature [34].

It is also worth noticing that in the case of B15, i.e. the blend containing the additive with the lowest degree of modification (see Table 1), a sharp peak in the mechanical loss spectrum was observed at about $80^{\circ} \mathrm{C}$, accounting for the $T_{\mathrm{g}}$ of the unmodified PVA chain segments.

The morphology of neat MPP and its blends was evaluated by SEM observation of the fracture surfaces of samples subject to impact tests. The results are presented in Figure 8.

As can be observed, pure MPP presents a smooth and homogenous surface, evidencing a brittle fracture of the sample. Figure $8 \mathrm{~b}$ and $8 \mathrm{~d}$ are similar to virgin MPP, however small, well dispersed additives particles covered by a layer of polypropylene matrix could be observed. In Figure $8 \mathrm{c}$ and $8 \mathrm{e}$ large additive particles are poorly dispersed within the MPP matrix, thus indicating a strong incompatibility between the polymers. In particular, several voids ascribed to removal of the additive due to the mechanical stress are present on the surface of B15. Therefore, it should be concluded that although all the blends are incompatible, the dispersion of polymeric additives is acceptable in B14 and B16, while severe incompatibility is observed for B15 and B17. It should be noted that, regarding the flame retardancy of a material in general, the low phase compatibility is not a drawback, yet it can negatively affect the mechanical properties of the final blend. However, from SEM analysis it is also evident that samples B15 and B17 show a more ductile fracture, as confirmed by the appearance of multiple fracture planes.

The mechanical properties of the blends prepared by melt mixing were characterized in order to evaluate the effect of the flame retardant additives, with a special view on the poor compatibility observed by SEM analysis. To this aim, tensile and impact tests were carried out on films and rod-shaped samples, respectively. Table 7 displays tensile modulus, yield stress, ultimate stress and elongation at break for all samples. It was observed that pure MPP was able to bear deformations up to $625 \%$, showing typical behaviour of ductile polymers: stress whitening followed by necking and drawing. On the other hand, a brittle behaviour was observed for the blends, and the tensile specimens failed just after the linear elastic region of the stress-strain curves. Since GPC 


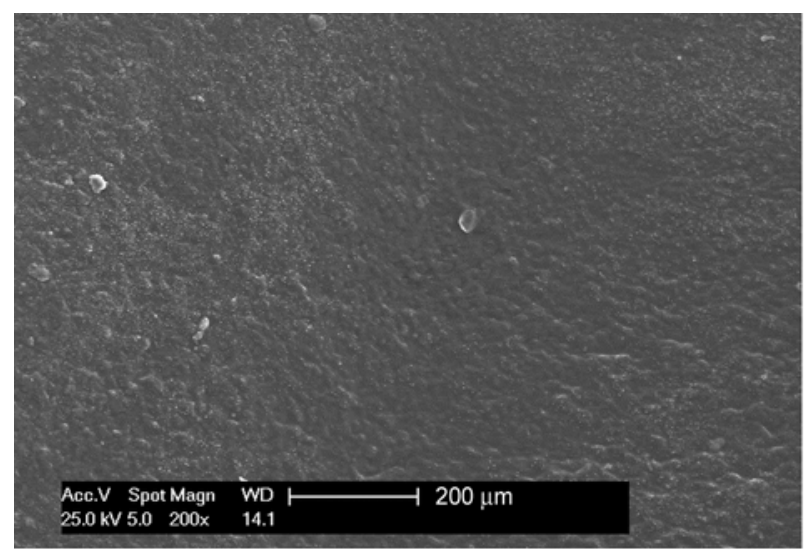

a)

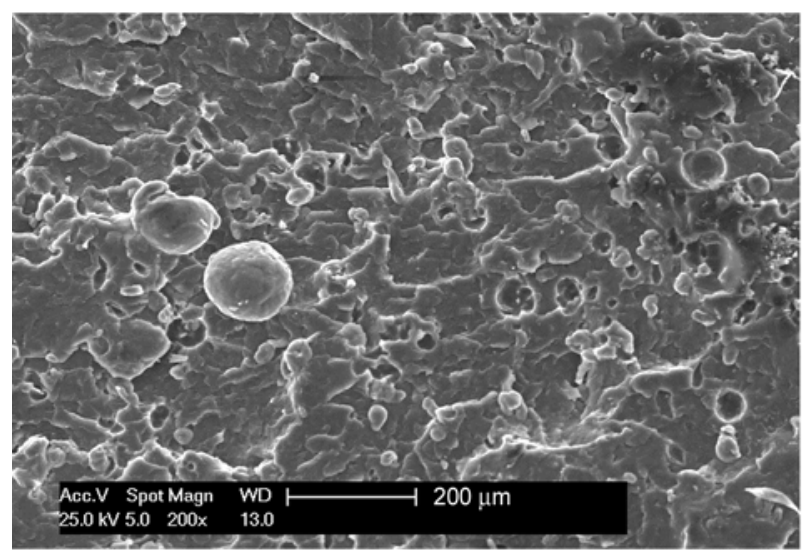

c)

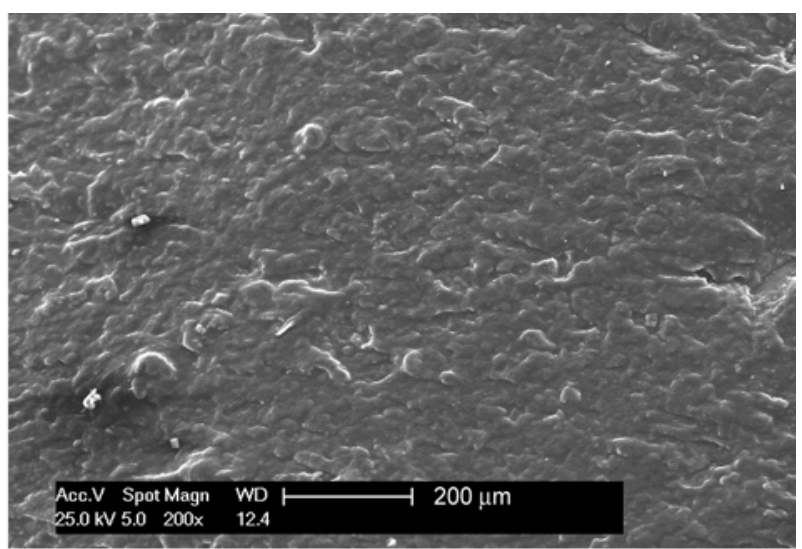

b)

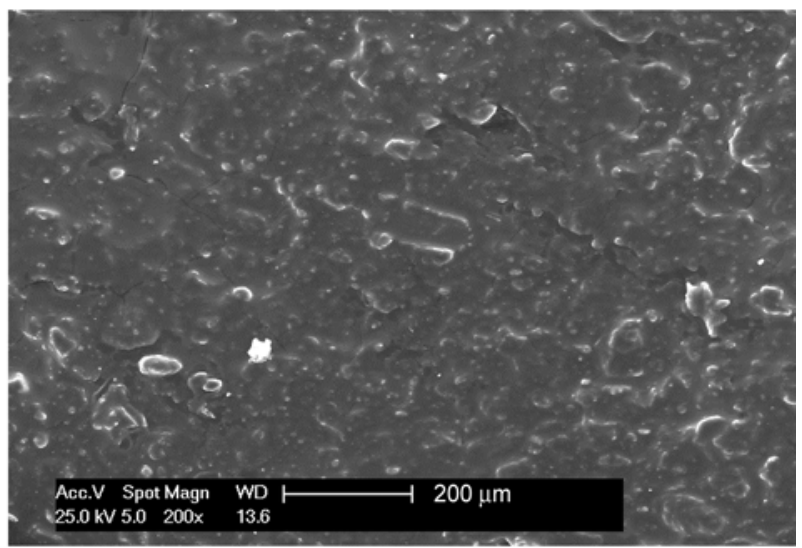

d)

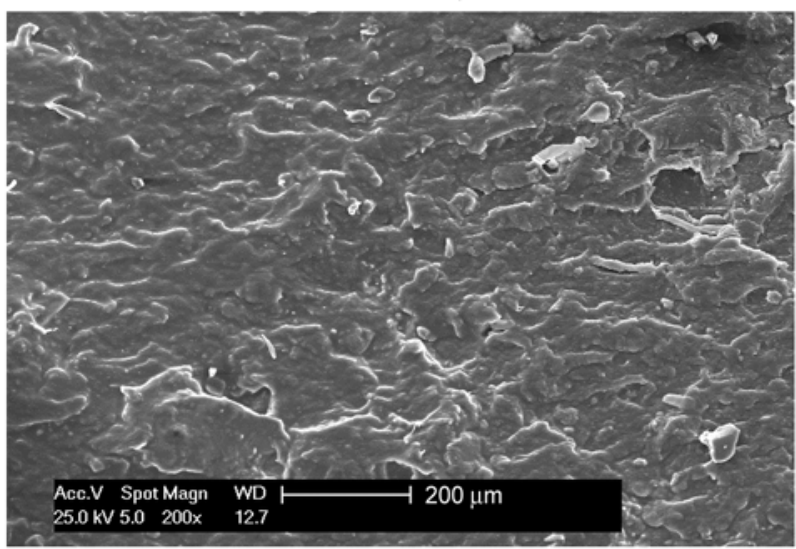

e)

Figure 8. SEM micrographs of the fracture surface of plain MPP (a) and its blends: B14 (b), B15 (c), B16 (d), and B17 (e)

Table 7. Mechanical tests results for MPP and its blends

\begin{tabular}{|l|c|c|c|c|c|}
\hline \multicolumn{1}{|c|}{ Sample } & $\begin{array}{c}\text { Elastic modulus } \\
{[\mathbf{M P a}]}\end{array}$ & $\begin{array}{c}\text { Yield stress } \\
{[\mathbf{M P a}]}\end{array}$ & $\begin{array}{c}\text { Ultimate stress } \\
{[\mathbf{M P a}]}\end{array}$ & $\begin{array}{c}\text { Elongation at break } \\
{[\%]}\end{array}$ & $\begin{array}{c}\text { Resilience } \\
{\left[\mathbf{k J} \cdot \mathbf{m}^{-2}\right]}\end{array}$ \\
\hline MPP & $970 \pm 0.2$ & $25 \pm 1.9$ & $32 \pm 5.8$ & $625 \pm 166.7$ & $1.8 \pm 0.2$ \\
\hline B14 & $1063 \pm 0.3$ & $26 \pm 1.0$ & $21 \pm 1.1$ & $12 \pm 2.5$ & $2.1 \pm 0.1$ \\
\hline B15 & $1135 \pm 0.2$ & $21 \pm 1.3$ & $19 \pm 1.2$ & $5 \pm 0.8$ & $2.7 \pm 0.2$ \\
\hline B16 & $1027 \pm 0.2$ & $22 \pm 0.9$ & $19 \pm 0.5$ & $16 \pm 3.9$ & $2.3 \pm 0.2$ \\
\hline B17 & $1032 \pm 0.2$ & $17 \pm 2.9$ & $16 \pm 2.4$ & $4 \pm 1.2$ & $2.4 \pm 0.3$ \\
\hline
\end{tabular}

results showed that polypropylene molecular weight was not affected by the presence of the additives, this behaviour can be due to the poor interfacial interaction between matrix and flame retardant additives.
As shown by SEM observations, the flame retardant additives were not well blended, but only dispersed in the matrix. In such a case, strength and elongation at break for filled systems depend on the 
state of the polymer-particle interface, since when the adhesion between filler and matrix is poor, a reduced stress transfer occurs at the interface, facilitating void opening and crack propagation $[35,36]$. Regarding elastic modulus and yield stress, the values obtained for the blends did not vary significantly with respect to that of the starting MPP. In particular, all the blends showed a slight increase in modulus, suggesting that the additive particles can act as weakly reinforcing fillers, whereas yield stress decreased to some extent. On the other hand, the ultimate stress and the elongation at break noticeably decreased compared to the starting MPP. It can be mentioned that the blends B14 and B16 showed slightly better elongation at break with respect to the other blends, which is probably due to better compatibility between the corresponding additive and the matrix, as observed by SEM micrograph analysis. Therefore, tensile tests showed that the elastic behaviour was not altered by the addition of the flame retardants, whereas the plastic behaviour was changed significantly. It must be noted that in several applications where PP must be flame retarded, elastic and impact properties of the material are crucial, while the plastic behaviour is not [37, 38]. Actually PP-based blends are widely used in many cases where good resistance to physical impulsive shocks is needed. For example, in automotive industry PPbased blends are constituents of many items, such as bumpers, in which the impact resistance is very important. Thus, it is convenient to evaluate impact properties of the materials where high toughness is required. The toughness of the starting MPP and its blends is displayed in Table 7 in terms of impact resilience. All blends showed higher toughness compared to MPP and B15 and B17 showed the highest resilience values. This can be related to SEM observations, which showed a more ductile fracture even though poor compatibility was observed for these blends. As already mentioned for the tensile tests, these results can be explained by considering that the size of the stiff particles dispersed into the matrix is in the range of tenths of microns, which make the additive particles acting as fillers. This can confer greater toughness to the matrix even with poor filler-to-matrix interaction. In fact, the impact energy can be partially dissipated in a mechanism, where the crack advancement is hindered by the presence of the stiffer additive particles. Crack deflection and twisting occur as a growing crack encounters the matrix-particle interfaces, which act primarily ahead of the crack tip to impede crack advance [39].

In summary, impact tests showed that the prepared blends can find application where toughness properties are required, while they increase slightly MPP flame retardancy, as it will be seen later.

\subsection{Thermal and flammability properties of the melt mixed blends}

Thermal stability and flame retardancy behaviour of the prepared melt mixed blends was characterized by TG analysis, LOI and cone calorimeter measurements.

Figure 9 shows the thermogravimetric curves of melt processed MPP and its blends in nitrogen atmosphere. From the curves it can be observed that neat MPP showed one weight loss step between 400 and $500^{\circ} \mathrm{C}$, while all blends displayed an additional degradation step in the $200-300^{\circ} \mathrm{C}$ temperature range. This additional weight loss process has been attributed to the decomposition of the additives initiated by thermal dehydration reactions, as confirmed by massive water evolution detected through mass spectrometry [11].

This step appeared at a slightly lower temperature in B15 with respect to the other blends, probably due to its higher content of $-\mathrm{OH}$ groups. Table 8 shows the onset temperature of weight loss, the temperature of the maximum rate of weight loss for both steps, and the char yield at $600^{\circ} \mathrm{C}$.

As can be seen in Figure 9 and Table 8, the second weight loss step of the blends, which is related to MPP degradation, was slightly delayed with respect to virgin MPP. Therefore, as it was observed for the blends obtained by dissolution, it is likely that the dehydration of additives led to a charred layer which

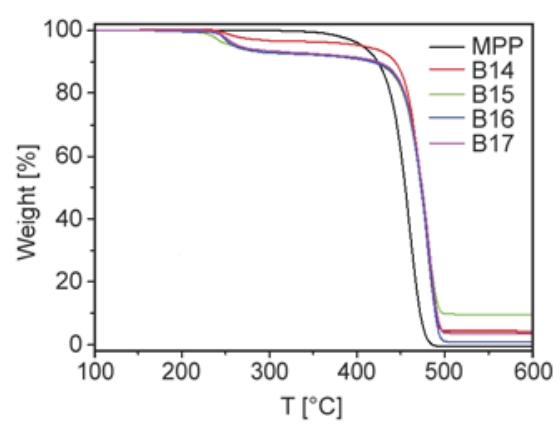

Figure 9. TG curves of MPP and its blends 
Table 8. Thermogravimetric and LOI results of neat MPP and its blends

\begin{tabular}{|c|c|c|c|c|c|c|c|}
\hline \multirow[b]{2}{*}{ Sample } & \multirow[b]{2}{*}{ Additive } & \multicolumn{2}{|c|}{ Step 1} & \multicolumn{2}{|c|}{ Step 2} & \multirow{2}{*}{$\begin{array}{c}\text { Char yield at } \\
600^{\circ} \mathrm{C} \\
{[\%]}\end{array}$} & \multirow{2}{*}{$\begin{array}{l}\text { LOI } \\
{[\%]}\end{array}$} \\
\hline & & $\begin{array}{l}\mathbf{T}_{\text {onset }} \\
{\left[{ }^{\circ} \mathbf{C}\right]}\end{array}$ & $\begin{array}{l}\mathbf{T}_{\max } \\
{\left[{ }^{\circ} \mathbf{C}\right]}\end{array}$ & $\begin{array}{l}\mathbf{T}_{\text {onset }} \\
{\left[{ }^{\circ} \mathbf{C}\right]}\end{array}$ & $\begin{array}{l}\mathbf{T}_{\max } \\
{\left[{ }^{\circ} \mathbf{C}\right]}\end{array}$ & & \\
\hline MPP & & & & 403 & 460 & - & $17.2 \pm 0.3$ \\
\hline B14 & $\mathrm{A} 1^{\prime}$ & 237 & 246 & 432 & 480 & 4.2 & $19.4 \pm 0.2$ \\
\hline B15 & $\mathrm{A} 2^{\prime}$ & 225 & 240 & 429 & 481 & 9.3 & $19.2 \pm 0.4$ \\
\hline B16 & B & 236 & 249 & 431 & 481 & 0.9 & $19.0 \pm 0.4$ \\
\hline B17 & $\mathrm{C}$ & 233 & 249 & 432 & 483 & 3.5 & $18.8 \pm 0.5$ \\
\hline
\end{tabular}

can protect polypropylene from degradation. From this point of view, no differences can be observed between the different additives used.

At the end of the second degradation step, neat MPP completely volatilized at $500^{\circ} \mathrm{C}$, whereas the blends yielded a residue at $600^{\circ} \mathrm{C}$. The highest amount of residue was associated to $\mathrm{B} 15$, as higher content of $-\mathrm{OH}$ groups favoured charring. B16 showed a lower char yield, probably due to the aliphatic nature of the side groups introduced. Therefore, as already discussed for the blends prepared by dissolution, the polymeric additives can confer flame retardancy also to the melt mixed blends.

As can be seen in Table 8, even with a small content of phosphorous ( $1 \mathrm{wt} \%$ ), LOI values increased to some extent in comparison with the plain polypropylene. Reduced dripping was also observed during the burning tests for the additivated samples. Thus, LOI values confirmed that the additives A1', $\mathrm{A} 2$ ', B and $\mathrm{C}$ are able to increase MPP flame retardancy in the melt mixed blends.

Cone calorimeter (CC) test is an effective method to study the flammability of materials. To further investigate the effect of the phosphorous modified PVAs on the flame behavior of PP, CC tests were performed using a heat flux of $35 \mathrm{~kW} \cdot \mathrm{m}^{-2}$. The heat release rate (HRR) and the mass loss curves of MPP and the blends are shown in Figure 10, while the relevant data obtained from $\mathrm{CC}$ measurements are listed in Table 9.

It was observed that the peak of heat release rate (PHRR) for neat PP was $1109.1 \mathrm{~kW} \cdot \mathrm{m}^{-2}$, and its total heat release (THR) was $100.7 \mathrm{MJ} \cdot \mathrm{m}^{-2}$. All the blends showed reduced values of both HRR and THR compared to MPP. In particular, B15 displayed a PHHR value about $25 \%$ lower than MPP, while a $24 \%$ decrease of the THR was measured for B14. These results suggest that the presence of phosphorous atoms associated with higher amounts of $-\mathrm{OH}$ groups increased the flame retardant properties of the blends. Based on the HRR curves, the fire growth rate (FGR) was calculated as the PHHR to $\mathrm{PHRR}_{\mathrm{t}}$ ratio $[40,41]$, to assess the fire hazard of the samples. In general, lower FGR values indicate that the time to flashover is delayed, then more time is allowed for people to escape fire. Slightly lower values of FGR were associated to the presence of the modified PVAs, and B15 showed a value of $5.29 \mathrm{~kW} \cdot \mathrm{m}^{-2} \mathrm{~s}^{-1}$, which represented a decrease of about $25 \%$ with respect to MPP. These results further demonstrated that blending polypropylene of PP with the phosphorous-modified PVA derivatives reduced the FGR of the blends provided that a significant number of free - $\mathrm{OH}$ groups is present. On the other hand,

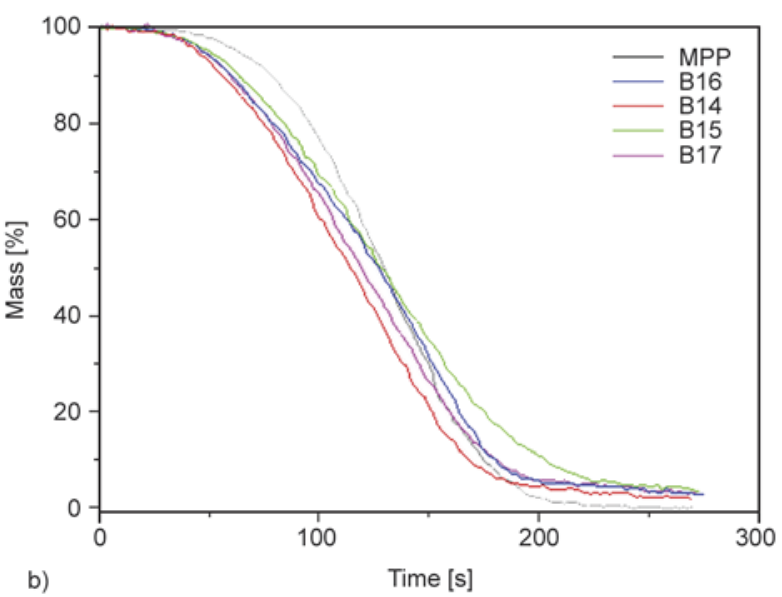

b)

a)

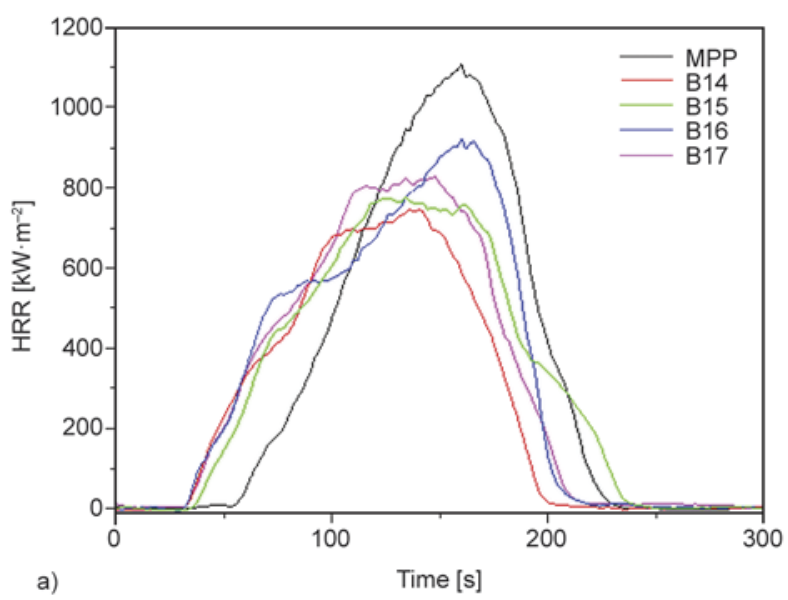

Figure 10. Heat release rate (a) and mass loss (b) curves of neat MPP and its blends obtained from cone calorimeter tests 
Table 9. Cone calorimeter data of neat PP and its blends

\begin{tabular}{|c|c|c|c|c|c|c|c|}
\hline Sample & $\begin{array}{c}\text { TTI }^{\mathbf{a}} \\
{[\mathrm{s}]}\end{array}$ & $\begin{array}{c}\text { PHRR }^{\mathbf{b}} \\
{\left[\mathrm{kW} \cdot \mathrm{m}^{-2}\right]}\end{array}$ & $\begin{array}{c}\text { PHRR }_{t}{ }^{\mathbf{c}} \\
{[\mathrm{s}]}\end{array}$ & $\begin{array}{c}\text { THR }^{\mathrm{d}} \\
{\left[\mathrm{MJ} \cdot \mathrm{m}^{-2}\right]}\end{array}$ & $\begin{array}{c}\mathbf{F G R}^{\mathrm{e}} \\
{\left[\mathrm{kW} \cdot \mathbf{m}^{-2} \cdot \mathbf{s}^{-1}\right]}\end{array}$ & $\begin{array}{c}\text { Average SPR } \\
{\left[\mathrm{m}^{2} \cdot \mathrm{s}^{-1}\right]}\end{array}$ & $\begin{array}{c}\text { Char residue } \\
\text { [wt\%] }\end{array}$ \\
\hline MPP & $48 \pm 3$ & $1109.1 \pm 74.2$ & $160 \pm 2$ & $100.7 \pm 1.8$ & $6.93 \pm 0.4$ & $0.019 \pm 0.001$ & not data \\
\hline B14 & $24 \pm 1$ & $862.8 \pm 31.2$ & $130 \pm 28$ & $78.4 \pm 7.1$ & $6.64 \pm 1.1$ & $0.021 \pm 0.003$ & $2.3 \pm 0.3$ \\
\hline B15 & $29 \pm 3$ & $841.0 \pm 105.4$ & $159 \pm 25$ & $94.9 \pm 3.4$ & $5.29 \pm 1.6$ & $0.022 \pm 0.001$ & $3.7 \pm 0.2$ \\
\hline B16 & $24 \pm 1$ & $927.9 \pm 19.5$ & $163 \pm 3$ & $97.6 \pm 1.3$ & $5.69 \pm 0.1$ & $0.022 \pm 0.002$ & $3.2 \pm 0.2$ \\
\hline B17 & $25 \pm 1$ & $904.3 \pm 50.1$ & $139 \pm 23$ & $92.4 \pm 6.5$ & $6.51 \pm 1.2$ & $0.021 \pm 0.002$ & $3.1 \pm 0.4$ \\
\hline
\end{tabular}

atime to ignition

${ }^{b}$ peak of the heat release rate curve

ctime to peak of the heat release rate curve

$\mathrm{d}_{\text {total heat release }}$

efire growth rate

$\mathrm{f}_{\text {average smoke production rate }}$

slightly increased values of the averaged smoke production rate (SPR) indicated that the additives can promote smoke release to some extent. As a final remark, it was observed that the residue after combustion increased for all the blends in comparison with MPP, demonstrating that the additives can enhance the stability of the residue also in presence of oxygen.

\section{Conclusions}

The results obtained on the flammability behavior of polypropylene through the use of purposely synthesized phosphorous-containing polyvinyl alcohol polymers are reported. The characterization of blends of polypropylene and different phosphorous-modified PVA derivatives bearing aliphatic (valeroyl group) or aromatic (benzoyl group) substituents showed that phase compatibility depended on the kind of substituting groups on the PVA backbone. It was also observed that grafting of the modified PVA on MPP may occur due to radical reactions arising during melt processing. TG, cone calorimeter and LOI measurements demonstrated that thermal stability and flame retardancy of the blends was improved, confirming that the phosphate moieties can act as carbonization promoters, in particular when a suitable amount of free hydroxyl groups is present. Tensile tests demonstrated that the elastic properties of the starting MPP were slightly influenced, while plastic behaviour was negatively affected. Impact test showed that the toughness of the blends was higher than that of pure MPP, likely due to a crack deflection and twisting mechanism.

\section{References}

[1] Bodzay B., Fejös M., Bocz K., Toldy A., Ronkay F., Marosi G.: Upgrading of recycled polypropylene by preparing flame retarded layered composite. Express Polymer Letters, 6, 895-902 (2012).

DOI: $10.3144 /$ expresspolymlett.2012.95

[2] Lv P., Wang Z., Hu K., Fan W.: Flammability and thermal degradation of flame retarded polypropylene composites containing melamine phosphate and pentaerythritol derivatives. Polymer Degradation and Stability, 90, 523-534 (2005).

DOI: $10.1016 /$ j.polymdegradstab.2005.04.003

[3] Li Q., Jiang P., Su Z., Wei P., Wang G., Tang X.: Synergistic effect of phosphorus, nitrogen, and silicon on flame-retardant properties and char yield in polypropylene. Journal of Applied Polymer Science, 96, 854860 (2005).

DOI: $10.1002 / a p p .21522$

[4] Fina A., Cuttica F., Camino G.: Ignition of polypropylene/montmorillonite nanocomposites. Polymer Degradation and Stability, 97, 2619-2626 (2012).

DOI: $10.1016 /$ j.polymdegradstab.2012.07.017

[5] Lu S-Y., Hamerton I.: Recent developments in the chemistry of halogen-free flame retardant polymers. Progress in Polymer Science, 27, 1661-1712 (2002). DOI: 10.1016/S0079-6700(02)00018-7

[6] Ebdon J. R., Jones M. S., Salamone J. C.: Polymeric materials encyclopedia. CRC Press, Boca Raton (1996).

[7] Bocz K., Bárány T., Toldy A., Bodzay B., Csontos I., Madi K., Marosi G.: Self-extinguishing polypropylene with a mass fraction of $9 \%$ intumescent additive $-\mathrm{A}$ new physical way for enhancing the fire retardant efficiency. Polymer Degradation and Stability, 98, 79-86 (2013).

DOI: $10.1016 /$ j.polymdegradstab.2012.10.029

[8] Chen X. L., Jiao C. M., Wang Y.: Synergistic effects of iron powder on intumescent flame retardant polypropylene system. Express Polymer Letters, 3, 359-365 (2009).

DOI: $10.3144 /$ expresspolymlett.2009.45 
[9] Anna P., Marosi G., Bertalan G., Márton A., Szép A.: Structure-property relationship in flame retardant polymers. Journal of Macromolecular Science Part B: Physics, 41, 1321-1330 (2002).

DOI: $10.1081 / \mathrm{MB}-120013102$

[10] Fina A., Bocchini S., Camino G.: Catalytic fire retardant nanocomposites. Polymer Degradation and Stability, 93, 1647-1655 (2008).

DOI: 10.1016/j.polymdegradstab.2008.05.027

[11] Huang N. H., Chen Z. J., Wang J. Q., Wei P.: Synergistic effects of sepiolite on intumescent flame retardant polypropylene. Express Polymer Letters, 4, 743-752 (2010).

DOI: 10.3144/expresspolymlett.2010.90

[12] Chiang W-Y., Hu H. C-H.: Phosphate-containing flameretardant polymers with good compatibility to polypropylene. II. Effect of the flame-retardant polymers on polypropylene. Journal of Applied Polymer Science, 82, 2399-2403 (2001).

DOI: $\underline{10.1002 / a p p .2090}$

[13] Wilkie C. A, Morgan A. B.: Fire retardancy of polymeric materials. CRC Press, Boca Raton (2010).

[14] Saucă S., Giamberini M., Reina J. A.: Flame retardant phosphorous-containing polymers obtained by chemically modifying poly(vinyl alcohol). Polymer Degradation and Stability, 98, 453-463 (2013).

DOI: $10.1016 /$ j.polymdegradstab.2012.07.045

[15] Banks M., Ebdon J. R., Johnson M.: Influence of covalently bound phosphorus-containing groups on the flammability of poly(vinyl alcohol), poly(ethylene-covinyl alcohol) and low-density polyethylene. Polymer, 34, 4547-4556 (1993). DOI: 10.1016/0032-3861(93)90163-5

[16] Avella M., Martuscelli E., Raimo M., Partch R., Gangolli S. G., Pascucci B.: Polypropylene reinforced with silicon carbide whiskers. Journal of Materials Science, 32, 2411-2416 (1997).

DOI: 10.1023/A:1018561308695

[17] Trongtorsak K., Supaphol P., Tantayanon S.: Effect of calcium stearate and pimelic acid addition on mechanical properties of heterophasic isotactic polypropylene/ ethylene-propylene rubber blend. Polymer Testing, 23, 533-539 (2004).

DOI: $10.1016 /$ j.polymertesting.2003.11.006

[18] Malucelli G., Priola A., Ferrero F., Quaglia A., Frigione M., Carfagna C.: Polyurethane resin-based adhesives: Curing reaction and properties of cured systems. International Journal of Adhesion and Adhesives, 25, 87-91 (2005).

DOI: $10.1016 /$ j.ijadhadh.2004.04.003

[19] Tomasetti E., Legras R., Henri-Mazeaud B., Nysten B.: Plastic deformation in polypropylene/(ethylene-propylene) copolymer blend during paint debonding. Polymer, 41, 6597-6602 (2000).

DOI: 10.1016/S0032-3861(99)00885-X
[20] Weidenfeller B., Höfer M., Schilling F.: Thermal and electrical properties of magnetite filled polymers. Composites Part A: Applied Science and Manufacturing, 33, 1041-1053 (2002). DOI: $10.1016 / \mathrm{S} 1359-835 \mathrm{X}(02) 00085-4$

[21] Rodionov A. G., Domareva N. M., Baulin A. A., Ponomareva Y. L., Ivanchev S. S.: Polydispersity of ethylene-propylene copolymers synthesized on supported Ziegler catalysts. Polymer Science U.S.S.R., 23, 17241732 (1981). DOI: $10.1016 / 0032-3950(81) 90410-\mathrm{X}$

[22] Tzoganakis C., Vlachopoulos J., Hamielec A. E., Shinozaki D. M.: Effect of molecular weight distribution on the rheological and mechanical properties of polypropylene. Polymer Engineering and Science, 29, 390-396 (1989). DOI: $10.1002 /$ pen.760290607

[23] Parent J. S., Bodsworth A., Sengupta S. S., Kontopoulou M., Chaudhary B. I., Poche D., Cousteaux S.: Structure-rheology relationships of long-chain branched polypropylene: Comparative analysis of acrylic and allylic coagent chemistry. Polymer, 50, 85-94 (2009). DOI: $10.1016 /$ j.polymer.2008.11.014

[24] Mendrek B., Trzebicka B.: Synthesis and characterization of well-defined poly(tert-butyl acrylate) star polymers. European Polymer Journal, 45, 1979-1993 (2009). DOI: $10.1016 /$ j.eurpolymj.2009.04.016

[25] Zhang C., Zhou Y., Liu Q., Li S., Perrier S., Zhao Y.: Facile synthesis of hyperbranched and star-shaped polymers by RAFT polymerization based on a polymerizable trithiocarbonate. Macromolecules, 44, 2034-2049 (2011). DOI: $10.1021 / \mathrm{ma1} 024736$

[26] Kaur I., Gautam N., Deepika Khanna N.: Modification of polypropylene through intercrosslinking graft copolymerization of poly(vinyl alcohol): Synthesis and characterization. Journal of Applied Polymer Science, 107, 2238-2245 (2008).

DOI: $10.1002 / a p p .27259$

[27] Jang J., Lee D. K.: Oxygen barrier properties of biaxially oriented polypropylene/polyvinyl alcohol blend films. Polymer, 45, 1599-1607 (2004). DOI: $10.1016 /$ j.polymer.2003.12.046

[28] Kontopoulou M., Wang W., Gopakumar T. G., Cheung C.: Effect of composition and comonomer type on the rheology, morphology and properties of ethylene- $\alpha$ olefin copolymer/polypropylene blends. Polymer, 44, 7495-7504 (2003).

DOI: 10.1016/j.polymer.2003.08.043

[29] Yamaguchi M., Miyata H., Nitta K-H.: Compatibility of binary blends of polypropylene with ethylene- $\alpha$ olefin copolymer. Journal of Applied Polymer Science, 62, 87-97 (2003).

DOI: 10.1002/(SICI)1097-4628(19961003)62:1<87:: AID-APP12>3.0.CO;2-5 
[30] De Rosa C., Auriemma F., Spera C.: Comparison between polymorphic behaviors of Ziegler-Natta and metallocene-made isotactic polypropylene: The role of the chain microstructure. Macromolecular Symposia, 218, 113-124 (2004).

DOI: $10.1002 /$ masy.200451412

[31] Yan H., Chen Y.: Blends of polypropylene and hyperbranched poly(phenylene sulphide) for production of dyeable PP fibres. Iranian Polymer Journal, 19, 791799 (2010).

[32] Vranjes N., Rek V.: Effect of EPDM on morphology, mechanical properties, crystallization behavior and viscoelastic properties of iPP+HDPE blends. Macromolecular Symposia, 258, 90-100 (2007).

DOI: $10.1002 /$ masy.200751210

[33] Jain S., Goossens H., van Duin M., Lemstra P.: Effect of in situ prepared silica nano-particles on non-isothermal crystallization of polypropylene. Polymer, 46, 8805-8818 (2005).

DOI: $10.1016 /$ j.polymer.2004.12.062

[34] Willbourn H.: The glass transition in polymers with the $\left(\mathrm{CH}_{2}\right)_{\mathrm{n}}$ group. Transactions of the Faraday Society, 54, 717-729 (1958). DOI: $10.1039 / \mathrm{tf} 9585400717$

[35] Ratanakamnuan U., Aht-Ong D.: Preparation and characterization of low-density polyethylene/banana starch films containing compatibilizer and photosensitizer. Journal of Applied Polymer Science, 100, 2717-2724 (2006).

DOI: 10.1002/app.23047
[36] Persico P., Ambrogi V., Carfagna C., Cerruti P. Ferrocino I., Mauriello G.: Nanocomposite polymer films containing carvacrol for antimicrobial active packaging. Polymer Engineering and Science, 49, 1447-1455 (2009).

DOI: 10.1002/pen.21191

[37] Hong C. H., Lee Y. B., Bae J. W., Jho J. Y., Nam B. U., Hwang T. W.: Preparation and mechanical properties of polypropylene/clay nanocomposites for automotive parts application. Journal of Applied Polymer Science, 98, 427-435 (2005).

DOI: 10.1002/app.21800

[38] Luda M. P., Brunella V., Guaratto D.: Characterisation of used PP-based car bumpers and their recycling properties. ISRN Materials Science, 2013, 531093/1531093/12 (2013).

DOI: $10.1155 / 2013 / 531093$

[39] Ritchie R. O.: The conflicts between strength and toughness. Nature Materials, 10, 817-822 (2011).

DOI: $10.1038 /$ nmat3115

[40] Shao Z-B., Deng C., Tan Y., Yu L., Chen M-J., Chen L., Wang Y-Z.: Ammonium polyphosphate chemically-modified with ethanolamine as an efficient intumescent flame retardant for polypropylene. Journal of Materials Chemistry A, 2, 13955-13965 (2014). DOI: $10.1039 / \mathrm{c} 4 \mathrm{ta} 02778 \mathrm{~g}$

[41] Breulet H., Steenhuizen T.: Fire testing of cables: Comparison of SBI with FIPEC/Europacable tests. Polymer Degradation and Stability, 88, 150-158 (2005). DOI: $10.1016 /$ j.polymdegradstab.2004.01.031 